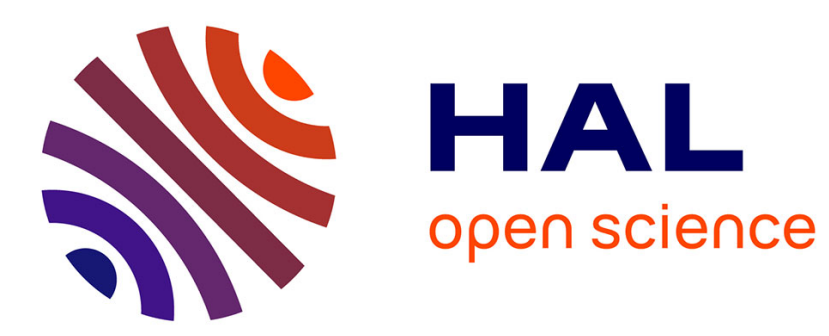

\title{
On the low velocity impact behaviour of glass plates
}

A. Ball, H. Mckenzie

\section{To cite this version:}

A. Ball, H. Mckenzie. On the low velocity impact behaviour of glass plates. Journal de Physique IV Proceedings, 1994, 04 (C8), pp.C8-783-C8-788. 10.1051/jp4:19948121 . jpa-00253364

\section{HAL Id: jpa-00253364 https://hal.science/jpa-00253364}

Submitted on 1 Jan 1994

HAL is a multi-disciplinary open access archive for the deposit and dissemination of scientific research documents, whether they are published or not. The documents may come from teaching and research institutions in France or abroad, or from public or private research centers.
L'archive ouverte pluridisciplinaire HAL, est destinée au dépôt et à la diffusion de documents scientifiques de niveau recherche, publiés ou non, émanant des établissements d'enseignement et de recherche français ou étrangers, des laboratoires publics ou privés. 


\title{
On the low velocity impact behaviour of glass plates
}

\author{
A. Ball and H.W. McKenzie* \\ Department of Materials Engineering, University of Cape Town, Rondebosch 7700, South Africa \\ * Solid Mechanics Group, Pilkington Technology Management Limited, Lathom, Lancashire, U.K.
}

\begin{abstract}
Circular plates of float glass with thicknesses between $3 \mathrm{~mm}$ and $12 \mathrm{~mm}$ and clamped at a radius of $65 \mathrm{~mm}$ have been impacted with a $3 \mathrm{~mm}$ diameter hardened steel ball travelling at velocities in the range of $10-50 \mathrm{~m} \mathrm{~s}^{-1}$. The fractures can be classified as Hertzian ring cracks at the contact zone with or without conical fractures; crushed impact zones on the front face which may be accompanied by cone cracks, median, radial and lateral cracking and in some cases star cracks propagating from the rear face. Examples of these will be described together with a qualitative predictive analysis for their occurrence as a function of impact velocity, plate thickness and surface condition. Of particular interest is the observation of crack bifurcation within the cone fractures in plates of thicknesses below $6 \mathrm{~mm}$.
\end{abstract}

\section{INTRODUCTION}

The study of elastic contact and the indentation and impact fracture of glass has attracted considerable attention over the last 100 years. Most attention has been given to the static indentation of a sphere against a semi-infinite solid $[1,2,3]$ whilst dynamic low velocity impact against semi-infinite targets has also been studied in some detail $[4,5,6,7,8,9]$. However, the most practical problem, that of the behaviour of clamped plates has surprisingly received little attention[10]. This problem is relevant to all types of glass windows, automobile, train and aircraft screens and security visors. This paper describes the experimental observations made as a function of plate thickness and in some instances the abrasion, using $1000 \mathrm{SiC}$ grit, of the surface has been used to modify the initiation of fractures. Further papers will examine in detail the bifurcation phenomena and the competition between fractures initiated from the from contact surface and the rear surface which experiences localised bending forces.

\section{EXPERIMENTAL}

A conventional airgun was used to propel $5 \mathrm{~mm}$ diameter 0,5 gram steel ball along a $1 \mathrm{~m}$ long barrel and impact on the specimen. The velocity of the projectile was determined by recording the time interval between the interruption of light beams placed $125 \mathrm{~mm}$ apart. The gun pressure was set to obtain desired impact velocities between 10 and $100 \mathrm{~m} \mathrm{~s}^{-1}$.

Specimens in the form of $150 \mathrm{~mm}$ diameter discs with thicknesses in the range $3 \mathrm{~mm}-12 \mathrm{~mm}$ are held in a "Perspex" holder. This arrangement clamps the plates on a circular contact radius of $65 \mathrm{~mm}$ and allows the plate to bend under impact. In order to determine threshold velocities for damage to a single test plate the gun was aligned so that the point of impact was $40 \mathrm{~mm}$ radial distance of the centre. Tests were then undertaken at incremental impact velocities at up to twelve different locations by simply rotating the perspex holder by $30^{\circ}$ in the solid steel backing plate. 
The impact sites were examined visually and photographed using a low power stereo optical and scanning electron microscope. The formation of a Hertzian ring crack was sufficient to mark the threshold velocity for damage. Several plates were tested in order to confirm a mean threshold velocity for a given specimen. The impact damage varied as a function of velocity of impact. In some cases abrasion of either or both surfaces using 1000 grit $\mathrm{SiC}$ paper has been undertaken in order to influence fracture behaviour. Several categories of damage have been designated (i) ring and small incomplete Hertzian cone cracks, (ii) Hertzian cones showing mist, hackle and bifurcation phenomena, (iii) complete perfect cones, (iv) complete, but damaged cones with crushing, median, radial and lateral cracks at the impact zone, (v) incomplete damaged cones with crushing median, radial and lateral cracks at the impact zone and (vi) star cracking initiated on the rear surfaces of the plates by bending stresses.

\section{RESULTS}

The map of fig. 1 has been drawn to categorise the types of damage observed in as-received float glass of various thicknesses as a function of impact velocity. It will be noted that the threshold velocity for the formation of small Hertzian rings falls with increasing plate thickness. Above this threshold, Hertzian rings with small incomplete cone cracks are observed. An example of this damage are shown in fig. 2 . In most cases the ring cracks are multiple and diametrical stylus traces indicate a slight depression within the ring and an annular raised area of damage around the ring. Abrasion of the upper surface promotes the initiation of this Hertzian cracking and eliminates the differential in threshold velocity between the plates of differing thicknesses.

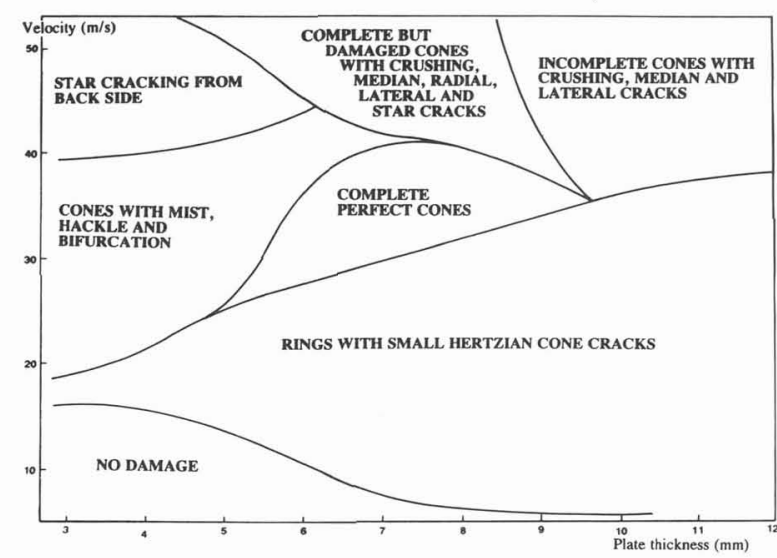

Fig. 1: A map of fracture types observed in glass plate of various thicknesses and velocities.

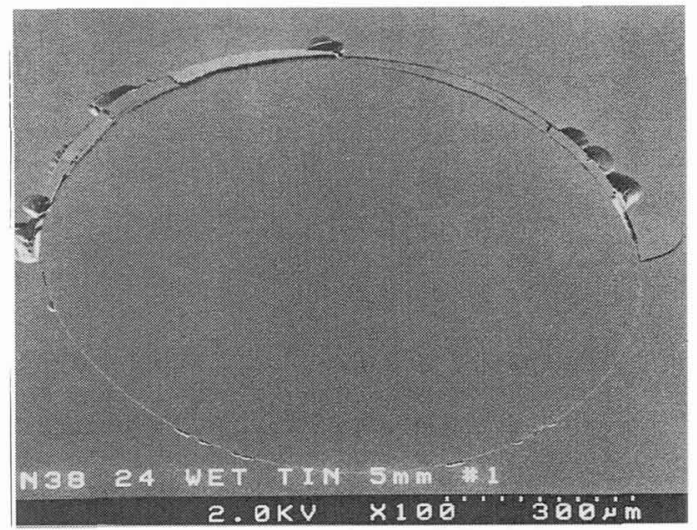

Fig. 2: Scanning electron micrograph of Hertzian ring crack.

At velocities above the regime of Hertzian ring formation, the propagation of cones can occur through the complete thicknesses of the plates. Perfect cones showing no hackle or bifurcation phenomena or crushing at the impact zone are formed for intermediate plate thicknesses $(6-8 \mathrm{~mm})$ and velocities of the order of 30 $-40 \mathrm{~m} \mathrm{~s}^{-1}$. However, close examination of these 'perfect' cones shows two types of fracture marks. A fan-like array of small steps or 'river lines' form around the original Hertzian ring as shown in fig. 3 . It is considered that these steps are required when the cone negotiates the change in angle during cone formation. The other markings observed in fig. 3 are the faint concentric circular markings which occur at various depths on the conical surface. These are considered to be mark moments of hesitation during the propagation of the cone crack. 

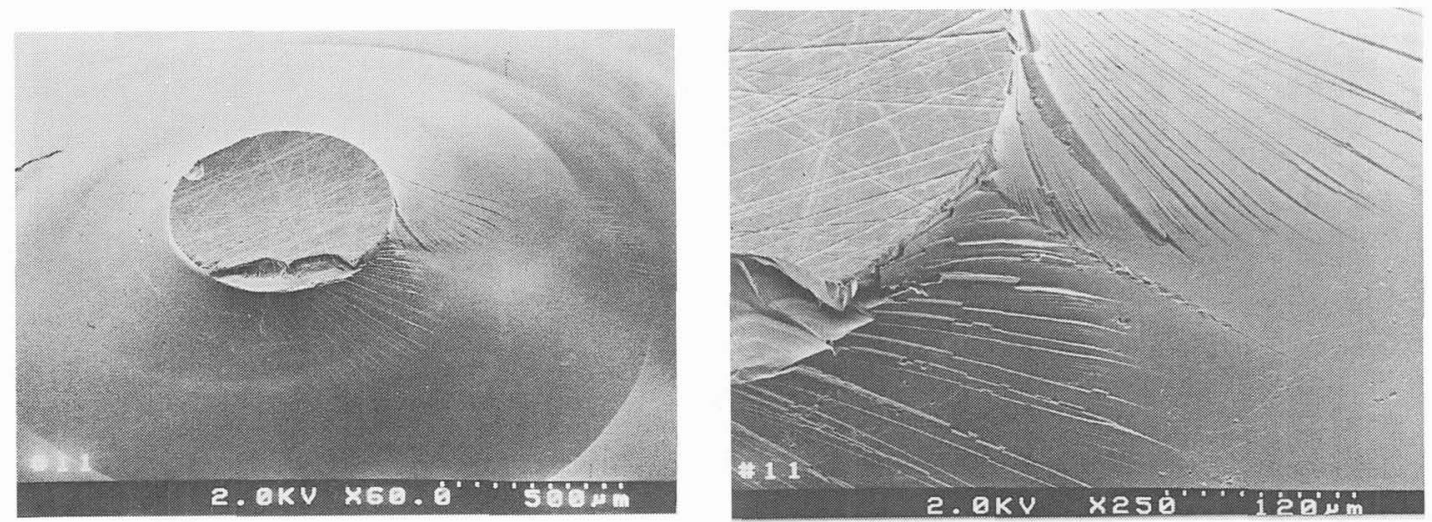

Figs. 3a and $b$ : A Hertzian cone formed in a scratched $3 \mathrm{~mm}$ glass plate. Note the fan-like array of steps around the initiating ring and the concentric hesitation marks around the cone.

The cones produced in thin plates (less than $5 \mathrm{~mm}$ ) vary in appearance as a function of impact velocity. At low velocities (less than $20 \mathrm{~m} \mathrm{~s}^{-1}$ ) perfect cones may be produced. As the impact velocity increases hackle markings and bifurcation phenomena are observed. Examples of this are shown in figs. $4 \mathrm{a}$ and $4 \mathrm{~b}$. The length of the mirror zone prior to hackle and bifurcation decreases systematically with increasing impact velocity. It should also be noted in fig. 4 that the radius of the initiating Hertzian ring crack increases with increasing velocity.
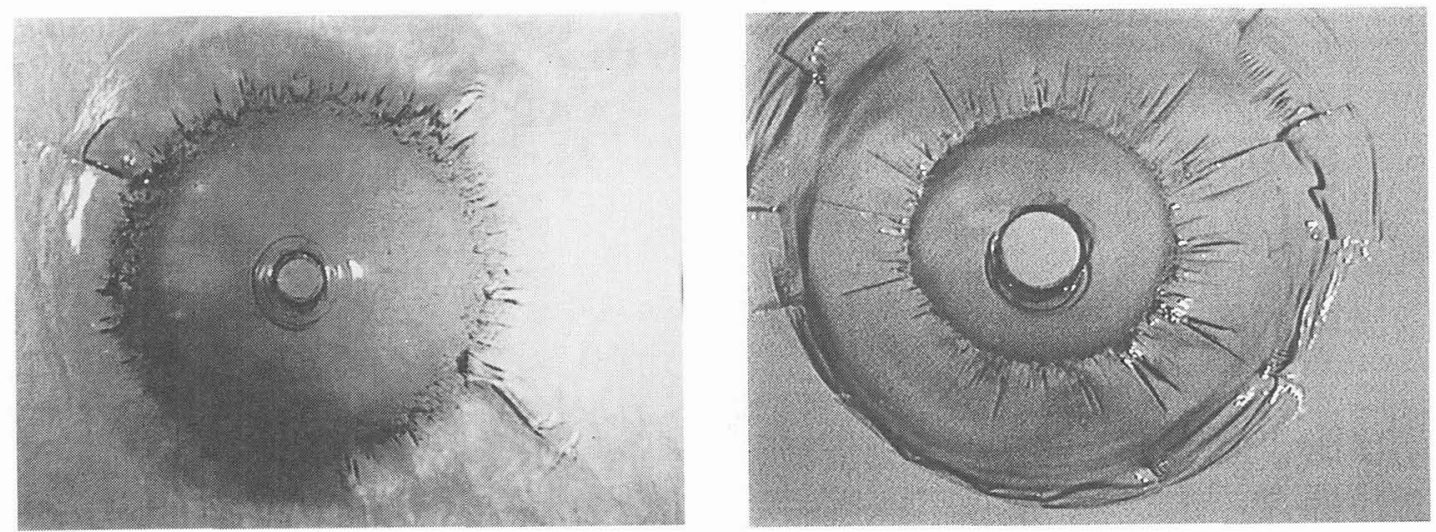

Figs. $4 a$ and $b$ : Cone cracks produced in $3 \mathrm{~mm}$ glasss at impact velocities of a) $20 \mathrm{~m} \mathrm{~s}^{-1}$ and b) $30 \mathrm{~m} \mathrm{~s}^{-1}$. The diameter of the initial ring crack increases with impact velocity. The circular zone of hackle occurs at a smaller radial distance for increasing impact velocities.

Figure 5 shows the mirror, mist and hackle zone in detail. The hackle zone is considered to be a period of increasing instability prior to bifurcation. The bifurcation results in an annular wedge-shaped fragment and a central 'spinning top' fragment. The annular wedge is shown in the scanning electron micrograph of fig. 6. It is extremely splintered and fragile. 


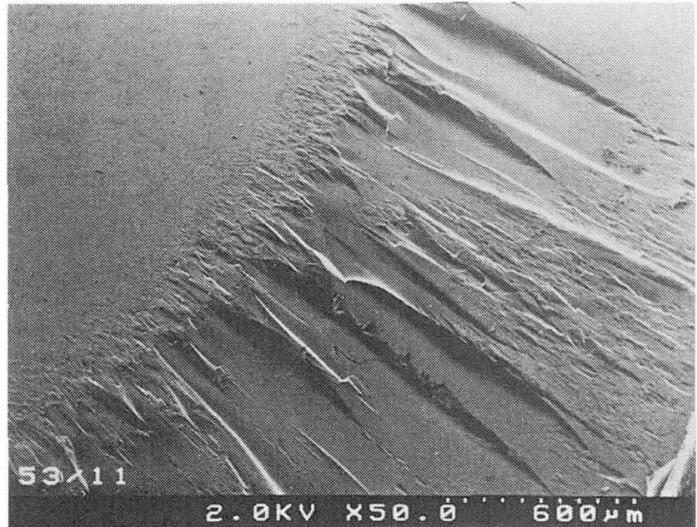

Fig. 5: A scanning electron micrograph of the hackle and bifurcation zone on a cone crack.

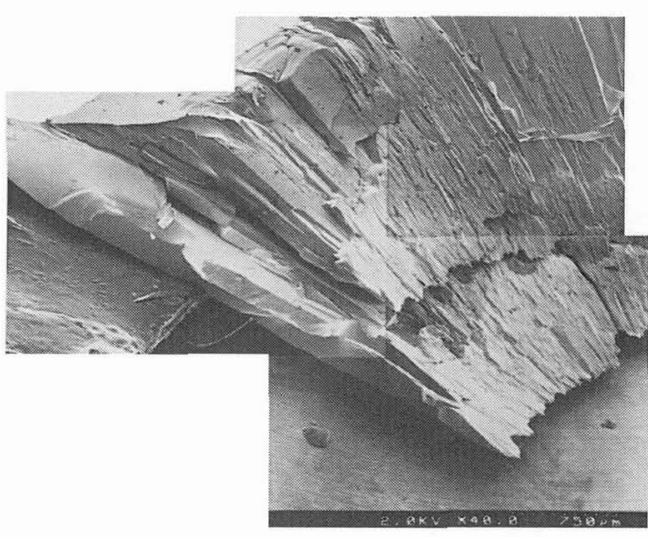

Fig. 6: The annular wedge produced by bifurcation of the Hertzian cone crack.

With increasing plate thickness (above $8 \mathrm{~mm}$ ) the production of complete and perfect cones is observed less frequently. Multiple ring cracks such as those shown in fig. 7 occur at the impact site and these are accompanied by radial cracks. Three such radial cracks approximately $120^{\circ}$ apart can be seen in this photograph. At higher velocities the impact zone becomes complex and has a 'white' appearance. The zone contains a multitude of incipient ring and cone cracks, median, radial and lateral cracks (fig. 8). This process dissipates energy and appears to make the propagation of Hertzian cone cracks through the thickness of the plate less probable. The cone cracks normally terminate within the thickness of the plate.

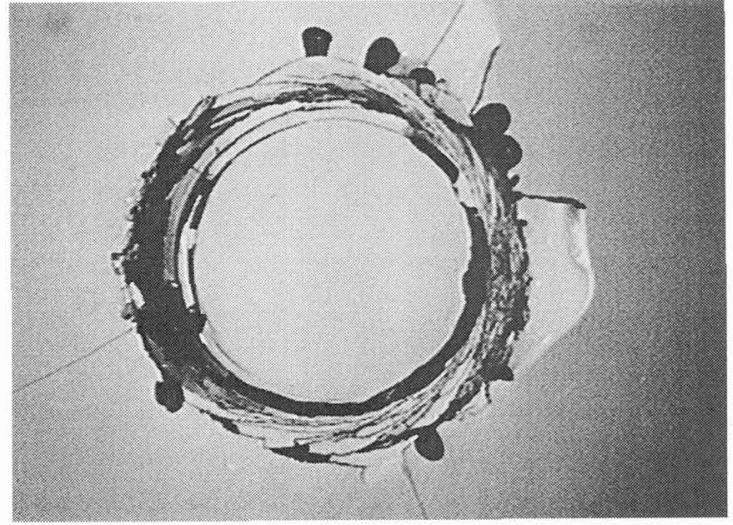

Fig. 7: Multiple Hertzian rings with radial cracks in $12 \mathrm{~mm}$ thick plate impacted at $30 \mathrm{~m} \mathrm{~s}^{-1}$.

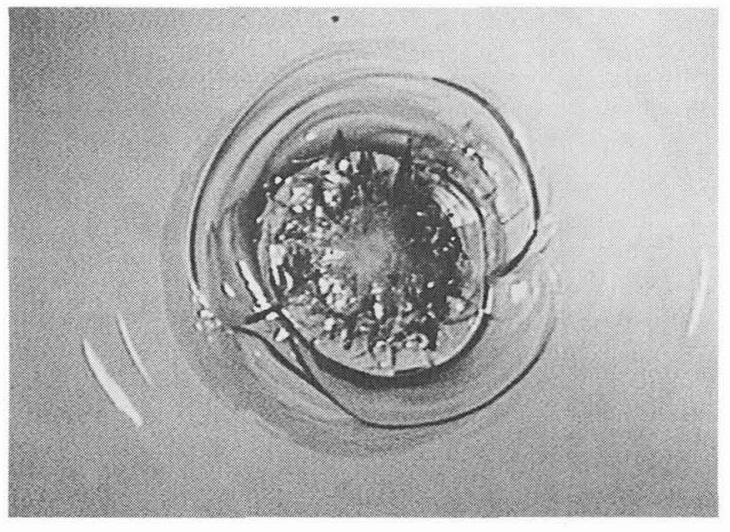

Fig. 8: A 'white'-crushed zone together with cone cracks, median, radial and lateral cracks produced in $12 \mathrm{~mm}$ thick plate impacted at $35 \mathrm{~m} \mathrm{~s}^{-1}$.

The thin plates (less than $5 \mathrm{~mm}$ ) show star cracks propagating from the area of maximum bending on the rear or non-contact surface when the impact velocity exceeds $35 \mathrm{~m} \mathrm{~s}^{-1}$. This star cracking initiates from a defect on the rear side which immediately bifurcates to produce a multitude of radial cracks which give a star-like appearance. This mode of cracking can be induced by abrading the lower surface with 1000 grit $\mathrm{SiC}$ paper and star cracking can be promoted in plates of $5 \mathrm{~mm}$ thick over an increased range of velocities. An example is shown in fig. 9 where the small cone crack initiated on the front contact surface can be seen together with the star cracking on the lower side. The two crack systems are in competition and occasionally the cone crack propagates through the plate whilst the star crack is propagating within the base of the cone; and the situation is depicted in the diagram of fig. 10 . 


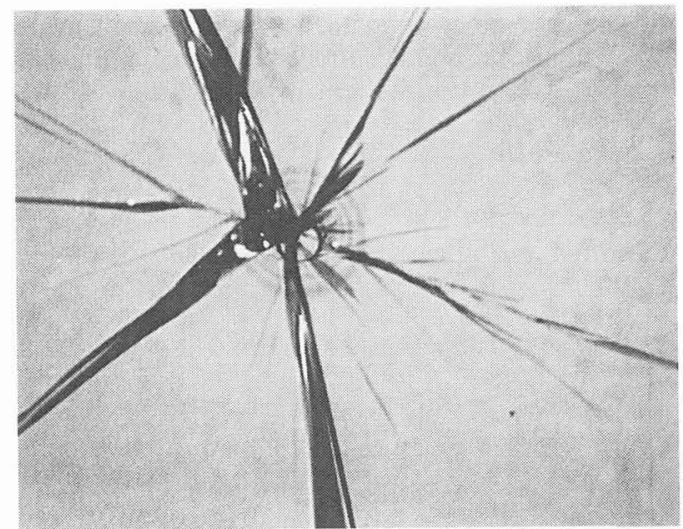

Fig. 9: Ring and cone formed on contact surface and simultaneous 'star' cracking on the reverse scratched side of a $5 \mathrm{~mm}$ sample.

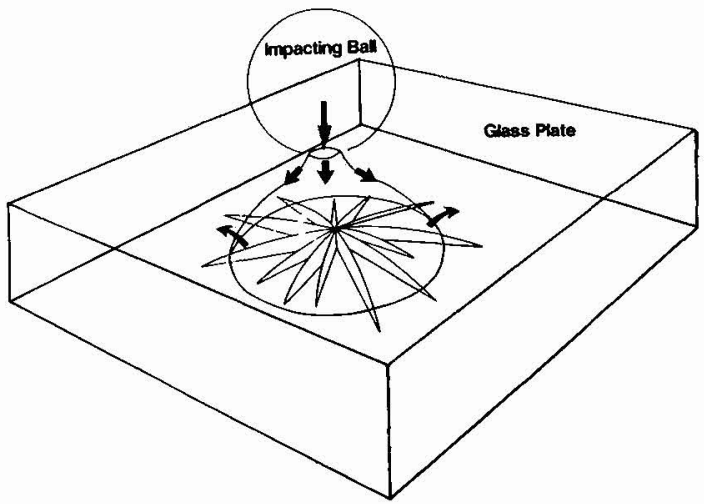

Fig. 10: A schematic illustration of the simultaneous propagation of cone cracks and star cracks.

\section{DISCUSSION}

A clamped plate of glass will experience two intense stress systems when impacted with a steel ball, namely the contact stress on the front surface and the localised bending stresses on the rear surface. The magnitude of these stresses will be determined by the size and velocity of the projectile, the clamping radius and the thickness of the plate. The initiation of fracture from either the front or rear surface will depend on the magnitude of these stresses in relation to the surface area experiencing the respective stress levels and the size distribution of the surface flaws. In the present experiment the impact velocity and plate thickness were varied systematically and some plate surfaces were scratched to promote cracking. All other factors were held constant.

Ignoring the mutual influence of bending of the magnitude on the contact stress and vice versa, the magnitude of the radial tensile stress around the contact zone is given as

$$
\sigma_{y y}=\left(\left(1-2 v_{1}\right) / 2\right) \pi^{-1}(5 \pi \rho / 3)^{1 / 5}(3 \mathrm{k} / 4)^{-4 / 5} \mathrm{~V}^{2 / 5}
$$

where $v$ is Poisson's ration, $\rho$ is the density of the steel ball, and $k$ is given as $\left(1-v_{1}^{2}\right) / E_{1}+\left(1-v_{2}^{2}\right) / E_{2}$ where the subscripts 1 and 2 refer to glass and steel respectively and $m$ is the impact velocity. The stress has a magnitude of approximately $1,5 \mathrm{GPa}$ for a velocity of $30 \mathrm{~m} \mathrm{~s}^{-1}$ and is localised in a thin $(\sim 0,1 \mathrm{~mm})$ annulus.

The magnitude of the bending stress on the near surface is given as

$$
\sigma_{b}=2 F\left(1+v_{1}\right)(0.48 \ln a / t+0.52) / t^{2}
$$

where $\mathrm{F}$ is the force produced by the impact, $a$ is the clamped radius and $\mathrm{t}$ is the plate thickness. This stress has a value of approximately $1 \mathrm{GPa}$ and $300 \mathrm{MPa}$ for $3 \mathrm{~mm}$ and $6 \mathrm{~mm}$ plates respectively for an impact velocity of $30 \mathrm{~ms}^{-1}$. The magnitude is strongly influenced by thickness. The bending stresses in thin plates approach the magnitude of the Hertzian contact stresses but sample a larger area of surface flaws. Thus 'star' cracking on the reverse side of thin plates becomes increasingly probable at high velocities as observed; abrasion of the rear surface encourages this form of cracking.

The presence of a hackle zone and bifurcation suggests that the propagation of Hertzian cone cracks through thin glass plates (less than $6 \mathrm{~mm}$ ) occurs at high velocities. The presence of 'hesitation' markings on cones produced in thicker plates and the truncated nature of the cones together with crushed impact 
zones in the thickest plates suggest that the energy required for their propagation becomes insufficient. Factors which may affect the propagation paths and depths include the contact time of the impacting ball, the presence of bending stresses within the plate and the internal reflection of tensile wares from the rear surface.

\section{REFERENCES}

1. Hertz H., J. reine angew. Math. 92 (1881) 156 (Reprinted in English in Hertz' Miscellaneous Papers, ch. 5. London, Macmillan.

2. Frank F.C. and Lawn B.R., Proc. R. Soc. A, 229 (1967) 291-306.

3. Wilshaw T.R., J. Phys. D: Appl. Phys. 4 (1971) 1567-1581.

4. Tillett, J.P.A., Proc. Phys. Soc. B69 (1956) 47-54.

5. Tsai Y.M. and Kolsky, H., J. Mech. Phys. Solids 15 (1967) 263-278.

6. Knight C.G, Swain M.V. and Chaudhri M.M., J. Mater.Sci. 12 (1977) 1573.

7. Chaudri M.M. and Kurkijan C.R., J. Amer. Ceram. 695 (1986).

8. Chaudri M.M. and Walley S.M., Phil. Mag. A37 153-165.

9. Field J.E., Sun Q. and Townsend D., Ballistic impact of ceramics, Conf. Series Inst. of Phys., 4th Int. Conf., on Mech. Properties of Materials at High Rates of Strain, Oxford (1989).

10. Zener, C., Phys, Rev. 59 (1941) 669-673. 